\title{
Effect of Obesity on the Work Health-Related Behaviors and Quality of Life of South African Mining Employees: A Pilot Study
}

\author{
Shereen C. Currie ${ }^{1}$, Michelle Smit ${ }^{2}$, Mondli Linda ${ }^{2} \&$ Jeanne Grace ${ }^{3}$ \\ ${ }^{1}$ Department of Sport Studies, Durban University of Technology, Durban, South Africa \\ ${ }^{2}$ Department of Biokinetics \& Sport Science, University of Zululand, Empangeni, South Africa \\ ${ }^{3}$ Discipline of Biokinetics, Exercise \& Leisure Sciences, University of KwaZulu-Natal, Durban, South Africa \\ Correspondence: Jeanne Grace, Discipline of Biokinetics, Exercise \& Leisure Sciences, University of Kwa \\ Zulu-Natal, Durban 4000, South Africa. Tel: 31-260-7985. E-mail: gracej@ukzn.ac.za
}

Received: September 14, 2017 Accepted: October 17, 2017 Online Published: October 31, 2017

doi:10.5539/gjhs.v9n12p122 URL: https://doi.org/10.5539/gjhs.v9n12p122

\begin{abstract}
Background: Obesity rates have increased precipitously with a significant economic impact. Aim: The aim of this study was to investigate the effect of obesity on the work health-related behaviors and quality of life (QoL) of employees of mining companies in South Africa.
\end{abstract}

Methods: Forty (40) subjects from three mining companies were assigned to three BMI categories: normal weight $\left(18.5-24.9 \mathrm{~kg} / \mathrm{m}^{2} ; \mathrm{n}=10\right)$, overweight $\left.25.0-29.9 \mathrm{~kg} / \mathrm{m}^{2} ; \mathrm{n}=15\right)$, and obese $\left(\geq 30.0 \mathrm{~kg} / \mathrm{m}^{2} ; \mathrm{n}=15\right)$. Subjects wore a BodyMedia ${ }^{\circledR}$ FIT armband for seven consecutive days, and completed: 1) the WHO QoL; and 2) the WHO Health at Work survey.

Results: There were significant differences in calorie expenditure $(p=0.033)$, activity patterns $(p=0.017)$, and number of steps walked daily $(\mathrm{p}=0.018)$ between the overweight and obese groups. Those of normal weight reported being significantly $(\mathrm{p}=0.041)$ more satisfied with their QoL and their leisure time activities and income $(p=0.017)$ than the obese. Almost all the significant differences with regard to work health-related behaviors were between the overweight and obese groups.

Conclusion: Results provide preliminary support for targeting weight loss as obesity may adversely influence employees' work health-related behaviors and QoL.

Keywords: BodyMedia ${ }^{\circledR}$ FIT armband, body mass index, health-related behaviors, lifestyle habits, obesity, physical activity patterns

\section{Introduction}

Obesity rates are rising rapidly around the world and becoming a growing concern in public health, with people becoming ever more sedentary (Sartorius, Veerman, Manyema, Chola, \& Hofman, 2015). Obesity affects 500 million people worldwide and this burden is projected to double by 2030 (Hill, Peters, Catenacci, \& Wyatt, 2008; WHO, 2014). Within sub-Saharan Africa, the South African population shows the highest prevalence of obesity (Micklesfield, Lambert, Hume, Chantler, Pienaar, Dickie, \& Goedecke, 2013), reported to be nearly 54\%, (WHO, 2015a).

Obesity is associated with increased morbidity and mortality (Hill et al., 2008; WHO, 2015b; James, 2005). Apart from the increased risk of developing a variety of medical conditions such as cardiovascular disease (Tibazarwa, Ntyintyane, Sliwa, Gerntholtz, Carrington, Wilkinson, \& Stewart, 2009), metabolic syndrome, hypertension (Van Zyl, Van der Merwe, Walsh, Groenewald, \& Van Rooyen, 2012) and diabetes (Peer, 2012), obesity appears to adversely affect an individual's capacity to live a full and active life. Thus, it has become increasingly evident that the problems associated with obesity are not simply restricted to causing or exacerbating medical conditions; this state also appears to have a substantial effect on a person's functional capacity and QoL (de Zwaan, Petersen, Kaerber, Burgmer, Nolting, Legenbauer, \& Herpertz, 2009; Taylor, Forhan, Vigod, McIntyre, \& Morrison, 2013). Obesity has been associated with impaired QoL in a variety of domains, including physical functioning, adequate sleep, occupation, self-esteem, social relationships and home environment (de Zwaan et al., 2009; Li, O'Connor, Zhou, \& Campbell, 2015). Additionally, obese individuals seem unconcerned about their health behaviors relating 
to their activity levels, number of steps taken daily, calorie expenditure and hours slept (Li et al., 2015; Gonnissen, Adam, Hursel, Rutters, Verhoef, \& Westerterp-Plantenga, 2013; Dwyer, Hosmer, Hosmer, Venn, Blizzard, Granger, \& Dunstan, 2007; Leibel, Rosenbaum, \& Hirsch, 1995). The QoL and health behaviors of employees of different weight working for South African mining companies, however, are unknown.

Of further concern is that the obesity epidemic directly impacts a nation's workforce, resulting in impaired productivity and increased expenditure on healthcare (Barkin, Heerman, Warren, \& Rennhoff, 2010). Also, employees manifest different health behaviors at work, including poor dietary habits, poor control over stress levels, and decreased physical activity levels having a negative effect on their body composition. In this regard researchers indicate that employees' working conditions contribute to the above unhealthy behaviours (Miranda, Gore, Boyer, Nobrega, \& Punnett, 2015). For example, obesity has been linked with night work, long working hours, sedentary work, psychosocial job strain, and job insecurity (Taylor et al., 2013; Miranda et al., 2015; Quist, Christensen, Christensen, Aust, Borg, \& Bjorner, 2013; Escoto, French, Harnack, Toomey, Hannan, \& Mitchell, 2010). Nonetheless, the literature is inconsistent on any of these putative associations. Among possible reasons both the lack of formal theoretical hypotheses and, somewhat in contrast, an incomplete set of risk factors are suggested (perhaps stemming from undue reliance on a priori models at this relatively early stage of accruing evidence) (Quist et al., 2013; Solovieva, Virtanen, \& Viikari-Juntura, 2013). Many of these studies have analyzed data from the general, working population abroad with no studies focusing on South African companies. To this end, the pilot study reported here investigated the impact of obesity on the QoL of mining employees and the status of their health at work. It formed part of a comprehensive study that aims to assess the impact of obesity and absence due to illness on economic costs incurred by South Africans at work.

\section{Methods}

This explorative-descriptive study used quantitative methods to describe and compare physical activity, sleep duration, calorie intake and expenditure, lifestyle habits, QoL and health of three select groups of employees.

\subsection{Subjects}

Forty (40) subjects between the ages of $24-49$ years (mean age $35.9 \pm 7.9$ years) from three South African mining companies volunteered for the study. Information about the research project were made available through the company's intranet platform. Recruitment of subjects was limited to admin personnel, and included professionals, managers, and clerical and administrative support. They were assigned to three groups, each comprising both men and women, according to their body mass index (BMI) - normal weight subjects with a BMI of $18.5-24.9 \mathrm{~kg} / \mathrm{m}^{2}(\mathrm{n}$ $=10)$, overweight subjects with a BMI of $25.0-29.9 \mathrm{~kg} / \mathrm{m}^{2}(\mathrm{n}=15)$ and the obese group with a BMI of $\geq 30.0 \mathrm{~kg} / \mathrm{m}^{2}$ $(\mathrm{n}=15)$ (Thompson, Gordon, \& Pescatello, 2014). The clinical characteristics of the subjects are displayed in Table 1 . The study sample was not differentiated by ethnic background, even though ethnicity may have an influence on the development of obesity.

Table 1. Subject characteristics $(\mathrm{M} \pm \mathrm{SD})$

\begin{tabular}{llll}
\hline Variables & Normal weight $(\mathbf{n}=\mathbf{1 0})$ & Overweight $(\mathbf{n}=\mathbf{1 5})$ & Obese $(\mathbf{n}=\mathbf{1 5})$ \\
\hline Age $($ years $)$ & $34.7 \pm 9.4$ & $36.6 \pm 7.5$ & $36.8 \pm 7.6$ \\
Height $(\mathrm{m})$ & $172.3 \pm 10.3$ & $167.6 \pm 11.7$ & $165.3 \pm 7.3$ \\
Weight $(\mathrm{kg})$ & $65.5 \pm 12.2$ & $76.6 \pm 10.9$ & $104.7 \pm 29.0$ \\
BMI $\left(\mathrm{kg} / \mathrm{m}^{2}\right)$ & $22.2 \pm 1.95$ & $27.2 \pm 1.63$ & $36.0 \pm 4.67$ \\
\hline
\end{tabular}

Note. $\mathrm{M}=$ mean; $\mathrm{SD}=$ standard deviation.

\subsection{Measuring Instruments}

The measurement criteria used (described in detail below) were body composition (height and body mass), physical activity (based on the results of using a BodyMedia ${ }^{\circledR} \mathrm{FIT}$ accelerometer), QoL (WHO QoL questionnaire), and work health-related behaviors (WHO Health at Work survey questionnaire).

\subsubsection{Body Composition Measurements}

Weight was recorded on a calibrated Robusta Seca 813 scale (Teraoka, South Africa) according to a standardized protocol (Thompson et al. 2014). Measurements were taken to the nearest $0.1 \mathrm{~kg}$. Height was measured in centimeters using a mobile stadiometer rod with a sliding ruler. Height and weight were used to calculate BMI (as weight $/$ height $^{2}-\mathrm{kg} / \mathrm{m}^{2}$ ) according to the protocol of Thompson et al. (2014). 


\subsubsection{BodyMedia ${ }^{\mathbb{B}}$ FIT Measurements}

The BodyMedia ${ }^{\circledR}$ FIT armband was used to measure energy expenditure (including steps taken), physical activity, exercise intensity, and sleep efficiency (duration and quality) (BodyMedia, 2014). All thirty subjects wore the armband for seven days, for 23 hours a day. They were given a thorough explanation of the purpose of the study, and received specific instructions on the use of the armband. Subjects were instructed to wear it on the back of the left upper-arm (triceps), with the silver sensors in contact with the skin at all times. The armband was removed only while the wearer was bathing, showering or swimming as it is not waterproof. After the seven-day measurement period, all the armbands were collected, and the data were downloaded for analysis using BodyMedia ${ }^{\circledR}$ software on the computer.

\subsubsection{Quality of Life Measurements}

The WHO Quality of Life questionnaire (WHOQOL) was used to measure subjects' QoL in various respects, such as health status, effect of pain, life enjoyment and meaning, ability to concentrate, sleep and energy levels, self-esteem and bodily appearance, ability to perform activities of daily living, money and leisure, work environment, and personal relationships (Harper, 1998). When answering the questions subjects were asked to keep in mind their standards, hopes, pleasures, and concerns. The questions were answered in relation to the previous four (4) weeks of ones' life. Subjects were required to answer the questions according to a Likert scale, with answer choices ranging from very poor/very dissatisfied/not at all/always to very good/very satisfied/an extreme amount/never.

\subsubsection{Work Health-Related Behavior Measurements}

The WHO Health at Work survey involved a comprehensive questionnaire covering information such as diagnosed diseases and conditions, lifestyle habits such as smoking and alcohol consumption, ability to concentrate, feelings of fatigue, problems with sleep, accidents and injuries in the workplace, visits to medical professionals, working hours, absenteeism, productivity, and demographic information (Kessler, Barber, Beck, Berglund, Cleary, McKenas, \& Wang, 2003). Questions were answered according to a Likert scale, with options ranging from no I don't have this condition/poor/nearly every day/all of the time to yes I have this condition and I am currently receiving professional treatment/excellent/never/none of the time.

\subsection{Statistical Analysis}

The experimental data were analyzed using the SPSS software program. For the analysis of the BodyMedia ${ }^{\circledR}$ FIT armband results the Kolmogorov-Smirnov test was performed to determine if the data were normally distributed $(p>0.2)$. As this proved to be the case, a parametric technique was used to analyze the data. A simple analysis of variance (ANOVA) was used to determine if there were significant differences between the three study groups (normal, overweight and obese). Significance was set as $p<0.05$. Once significant differences were established, a Tukey's HSD test was conducted to determine between which specific groups the differences lay. For the analysis of the various questionnaires, Pearson's chi-squared test was used to determine whether there was a significant difference between the expected and the observed frequencies in one or more categories.

\subsection{Validity and Reliability of Measuring Instruments}

The validity and reliability of the data were ensured as follows:

- Body mass and height were measured according to standardized methods (Thompson et al., 2014).

- Valid and reliable questionnaires were used. Domain scores produced by the WHOQOL correlate highly (0.89 or above) with WHOQOL-100 domain scores (calculated on a four-domain structure). WHOQOL domain scores demonstrated good discriminant validity, content validity, internal consistency and test-retest reliability (Harper, 1998; Skevington, Lotfy, \& O'Connell, 2004).

- The WHO Health at Work survey has been used previously, and proved to be valid and reliable (Kessler et al., 2006).

- The BodyMedia ${ }^{\circledR}$ FIT armband has been clinically proven accurately to measure physical activity levels and calories expended (de Cristofaro, Pietrobelli, Dragani, Malatesta, Arzeni, Luciani, \& Battistini, 2005; Robertson, 2004).

\section{Results}

The work health-related behaviors of the subjects are displayed in Table 2; Table 3 explains where significant differences lie between groups. Significant differences were noted between the three groups for calorie expenditure $(\mathrm{p}=0.033)$, amount of daily activity $(\mathrm{p}=0.037)$, number of steps taken daily $(\mathrm{p}=0.017)$, and hours 
slept per night $(p=0.045)$. No significant differences were seen in calorie intake $(p=0.227)$, sleep efficiency $(p=$ $0.266)$, and hours spent lying down $(\mathrm{p}=0.216)$, with average physical activity intensity approaching significance $(\mathrm{p}=0.095)$.

Table 2. Work health-related behaviors of normal, overweight and obese subjects

\begin{tabular}{llllll}
\hline Variables & Normal & Overweight & Obese & F & p \\
\hline Calex (kCal) & $2,599 \pm 490$ & $3,256 \pm 839$ & $2,514 \pm 514$ & 3.88 & $0.033^{*}$ \\
Calin (kCal) & $1,314 \pm 425$ & $1,596 \pm 522$ & $1,205 \pm 491$ & 1.57 & 0.227 \\
Physical Activity (hours) & $3.74 \pm 0.91$ & $3.93 \pm 1.27$ & $2.30 \pm 1.57$ & 4.77 & $0.037^{*}$ \\
Steps (steps/day) & $6,973 \pm 1,412$ & $8,322 \pm 1,733$ & $5,378 \pm 2,602$ & 4.68 & $0.017^{*}$ \\
Pa int (METs) & $1.79 \pm 0.27$ & $1.85 \pm 0.29$ & $1.58 \pm 0.29$ & 2.57 & 0.095 \\
Sleep ef (\%) & $79.0 \pm 6.55$ & $80.3 \pm 7.43$ & $74.2 \pm 10.3$ & 1.39 & 0.266 \\
Lying (hours) & $9.17 \pm 0.87$ & $8.16 \pm 1.64$ & $8.35 \pm 1.10$ & 1.63 & 0.216 \\
Sleep (hours) & $7.21 \pm 0.82$ & $6.41 \pm 0.69$ & $6.18 \pm 1.00$ & 3.50 & $0.045^{*}$ \\
\hline
\end{tabular}

Note. ${ }^{*} \mathrm{p}<0.05$; Calex = calorie expenditure; Calin = calorie intake; Activity = activity recorded; Steps = steps taken per day; $\mathrm{Pa}$ int $=$ physical activity intensity; METs = metabolic equivalent; Sleep ef $=$ sleep efficiency; Lying $=$ number of hours lying down per day; Sleep = number of hours slept per day.

It is clear from Table 3 that significant differences are only noted between the overweight and the obese groups with regard to calorie expenditure $(p=0.033)$, physical activity patterns $(p=0.037)$ and number of steps taken $(p=$ 0.017). Overweight individuals reported being significantly more active and took more steps daily than obese individuals. The physical activity levels of the normal weight group were higher than those of the obese, and approached significance $(\mathrm{p}=0.057)$. No significant differences were seen between the normal weight and overweight groups with regard to calorie expenditure, physical activity, and steps taken. Overweight subjects spent less time sleeping than those of normal weight, yet the sleep efficiency of the overweight group was greater than that of normal subjects (though not significantly different; Table 2). Table 3 indicates that those of normal weight recorded the most hours of sleep, with the obese group sleeping the least. Those of normal weight spent significantly $(p=0.045)$ more time sleeping, and demonstrated greater sleep efficiency than the obese.

Table 3. Significant differences specific to normal, overweight and obese subjects

\begin{tabular}{|c|c|c|c|}
\hline Calex (kCal) & Normal $(n=10)$ & O/weight $(n=15)$ & Obese $(n=15)$ \\
\hline \multicolumn{4}{|l|}{ Normal $(\mathrm{M}=2599)$} \\
\hline $\mathrm{O} /$ weight $(\mathrm{M}=3256)$ & 0.103 & & \\
\hline Obese $(M=2514)$ & 0.944 & $0.033^{*}$ & \\
\hline \multicolumn{4}{|c|}{ Physical Activity (hours) } \\
\hline \multicolumn{4}{|l|}{ Normal $(\mathrm{M}=3.74)$} \\
\hline $\mathrm{O} /$ weight $(\mathrm{M}=3.93)$ & 0.963 & & \\
\hline Obese $(\mathrm{M}=2.29)$ & 0.057 & $0.037^{*}$ & \\
\hline \multicolumn{4}{|l|}{ Steps (steps/day) } \\
\hline \multicolumn{4}{|l|}{ Normal $(\mathrm{M}=6973)$} \\
\hline $\mathrm{O} /$ weight $(\mathrm{M}=8322)$ & 0.461 & & \\
\hline Obese $(\mathrm{M}=5378)$ & 0.231 & $0.017^{*}$ & \\
\hline \multicolumn{4}{|l|}{ Sleep (hours) } \\
\hline \multicolumn{4}{|l|}{ Normal $(\mathrm{M}=7.21)$} \\
\hline $\mathrm{O} /$ weight $(\mathrm{M}=6.41)$ & 0.213 & & \\
\hline Obese $(\mathrm{M}=6.18)$ & $0.045^{*}$ & 0.835 & \\
\hline
\end{tabular}

Note. $\mathrm{O} /$ weight $=$ overweight; $* \mathrm{p}<0.05$. 
The results of the WHO QoL questionnaire indicate some significant differences between the study groups (Table 4). All of the significant differences were found between the normal weight and obese subjects. The first significant difference was in the QoL ratings, for which normal weight subjects reported being significantly $(\mathrm{p}=$ 0.041 ) more satisfied with their QoL than the obese. Quality of life is also associated with perceived satisfaction with income and leisure activities as well as general contentment with life. The results showed a significant difference $(p=0.025)$ between normal weight and obese subjects in these respects. The largest significant difference $(p=0.017)$ was between normal weight and obese subjects with regard to their general satisfaction with life; those of normal weight reported being 'very satisfied with life in general' compared to the obese, who were only 'satisfied with life'.

Table 4. WHO QoL questionnaire variables between normal, overweight and obese groups

\begin{tabular}{llll}
\hline WHO QoL variable & $\chi^{2}$ value & df & p \\
\hline Q1: Quality of life & 13.13 & 6 & $0.041^{*}$ \\
Q2: Satisfaction with health & 10.60 & 6 & 0.101 \\
Q3 \& Q4: Effect of pain \& medical treatment on quality of life & 7.29 & 6 & 0.295 \\
Q5 \& Q6: Life enjoyment \& meaning & 6.68 & 4 & 0.154 \\
Q7: Ability to concentrate & 9.65 & 6 & 0.140 \\
Q8 \& 9: Safety \& health of physical environment & 6.28 & 4 & 0.179 \\
Q10: Energy levels & 8.57 & 6 & 0.199 \\
Q11: Bodily appearance & 6.40 & 6 & 0.380 \\
Q12-Q14: Money \& leisure & 11.16 & 4 & $0.025^{*}$ \\
Q15-Q25: Satisfaction with sleep, work, self, relationships, living & 8.14 & 2 & $0.017^{*}$ \\
space, health services \& transport & 7.22 & 6 & 0.301 \\
Q26: Negative feelings & & & \\
\hline
\end{tabular}

Note. $* \mathrm{p}<0.05$.

Table 5 shows the results of the WHO Health at Work survey relating to subjects' diagnosed diseases/state of health, lifestyle habits such as smoking and alcohol consumption, ability to concentrate, feelings of fatigue, mental health symptoms, diagnosed chronic conditions, bothersome symptoms, and productivity. The section of the WHO Health at Work survey relating to concentration asked subjects if they had difficulty organizing matters for a work-related task, problems remembering appointments, delayed tasks requiring concentration, or if they fidgeted if they had to sit still for an extended period. There was a significant difference $(p=0.032)$ between the normal weight and obese groups with regard to problems with concentration; whereas the former reported rarely experiencing such problems, the obese had difficulty with their concentration more often. Although no other significant differences were found between the three groups with regard to the health at work survey, the difference between smoking habits of obese subjects compared to normal weight subjects approached significance $(\mathrm{p}=$ 0.091). 
Table 5. WHO Health at Work survey variables for normal, overweight and obese groups

\begin{tabular}{lcll}
\hline WHO Health at Work variable & Value & df & p \\
\hline A1 \& A2: Overall \& mental health & 6.06 & 8 & 0.640 \\
A3: Diagnosed orthopedic \& chronic conditions & 7.96 & 6 & 0.241 \\
A7: Diagnosed chronic conditions & 6.04 & 8 & 0.643 \\
A9: Smoking & 10.92 & 6 & 0.091 \\
A10: Drinking habits & 11.68 & 8 & 0.166 \\
A10a: Average number of drinks/day & 4.51 & 4 & 0.341 \\
A10b: Frequency of consuming $>$ 5 drinks/day & 8.46 & 6 & 0.207 \\
A11-A13: Irritability & 1.22 & 2 & 0.542 \\
A15: Concentration & 16.87 & 8 & $0.032^{*}$ \\
A16: Tiredness & 11.22 & 8 & 0.190 \\
A18: Bothersome abdominal symptoms & 7.94 & 6 & 0.242 \\
A20: Shortness of breath & 1.81 & 2 & 0.404 \\
A27: Bothersome symptoms & 6.45 & 6 & 0.375 \\
A28: Mental health symptoms & 0.73 & 2 & 0.696 \\
B12: Productivity & 2.85 & 2 & 0.241 \\
\hline
\end{tabular}

Note. $* \mathrm{p}<0.05$.

\section{Discussion}

The pilot study took place as to date no evidence is available on the impact of obesity on the work health-related behaviors, quality of life and health status at work of select employees from mining companies in South Africa. Our preliminary findings indicate that almost all the significant differences with regard to their work health-related behaviors, except for the number of hours slept, were between the overweight and obese groups. This was unexpected as it was postulated that the main differences would be between the normal weight and obese subjects. The fact that our study subjects were divided into three different groups on the basis of only BMI may have contributed to these surprising findings. BMI measures excess weight rather than body fatness and does not differentiate between bone, muscle and fat (Burkhauser \& Cawley, 2008); thus lean body mass was not considered. Muscle mass compared to overall body weight needs to be considered as a more reliable predictor of resting energy expenditure (Johnstone, Murison, Duncan, Rance, \& Speakman, 2005; MacArdle, Katch, \& Katch, 2010). It may be possible that some of the subjects placed in the overweight group were actually physically active individuals, with relatively large amounts of muscle mass, thus explaining the significant differences in the two components of physical activity (amount of daily activity and number of steps taken per day) of the study. Previous findings in this regard are inconsistent (Chan, Ryan, \& Tudor-Locke, 2004) indicated that BMI is not significantly related to changes in step number; Dwyer et al. (2007) found an inverse association between number of daily steps and obesity; and Li et al. (2015) reported differing patterns of physical activity exhibited by normal weight, overweight, and obese people which are consistent with their weight status - leaner people are more physically active.

When analyzing total calorie expenditure, a significant difference was once again found between overweight and obese individuals, such that the former showed higher total calorie expenditure than the obese. Basic energy accounting, in terms of which individuals expend calories in three ways, namely basal metabolic rate (BMR), diet-induced thermogenesis as well as energy spent on daily physical activity, may explain the difference between the overweight and obese individuals (McArdle et al., 2010; Cutler, Glaeser, \& Shapiro, 2003). BMR accounts for approximately $60 \%$ of total energy expenditure, and includes the metabolic cost of processes such as the maintenance of body systems and resting cardiopulmonary activity. The thermic effect of feeding accounts for approximately $10 \%$ of total energy expenditure, and refers to the calories expended in the digestion, transport, and assimilation of nutrients. Energy expended during physical activity represents approximately $30 \%$ of total energy output (McArdle et al., 2010). As indicated earlier, the overweight subjects in our study were significantly more physically active than the obese group, possibly with a greater muscle mass, and therefore they would have had a higher BMR due to their metabolically active musculature. In agreement with findings by other researchers, an 
elevated BMR, in conjunction with more physical activity performed, could explain the higher calorie expenditure of the overweight group compared to the normal weight and obese groups (Cutler et al., 2003).

Our study's finding that individuals of normal weight spent significantly more time sleeping, and enjoyed greater sleep efficiency, than the obese group was consistent with previous observations that less sleep may contribute to weight gain (Gonnisen et al., 2013; Nishitani, Sakakibara, \& Akiyama, 2012), and that weight gain may lead to reduced sleep (Nishitania et al., 2012; Fogelholm, Kronholm, Kukkonen-Harjula, Partonen, Partinen, \& Härmä, 2007)

A large body of evidence suggests that obesity has been associated with an impaired QoL in a variety of domains, such as physical functioning, self-esteem, health status, ability to enjoy life, social relationships, and sleep disorders (de Zwaan et al., 2009; Taylor et al., 2013), which support the findings of our study. However, Atlantis and Baker reported a weak relationship between obesity and QoL (Atlantis \& Baker, 2008).

The significant difference between normal weight and obese subjects with regard to problems with concentration - such that obese subjects experienced difficulty with their concentration more often - are consistent with previous research (Barkin et al., 2010; Forhan, Law, Taylor, \& Vrkljan, 2012). Also reflecting other reports, our study found that fewer normal weight subjects smoked than their obese counterparts (Miranda et al., 2015).

\section{Conclusion}

The preliminary results has added to the body of knowledge on the work health-related behaviors, QoL and health status at work of South African mining employees; more specifically and quite surprisingly, overweight subjects expended more calories and were physically more active than their obese counterparts. It was expected that any significant difference would be found between obese and normal weight individuals. However, with regard to the QoL and health status of our sample, our results correlate with previous findings that obese individuals also had a poorer perceived quality of life and concentration levels than those of normal weight.

The pilot study warrants further studies to confirm the impact obesity may have on employees' physical and mental health, functional capacity, and quality of life. Furthermore, the present pilot study suggests that these results needs to be acknowledged by those at school, at work generally, as well as in South Africa at large, to help combat obesity in the country.

\section{Compliance with Ethical Standards}

All procedures performed in studies involving human subjects were in accordance with the ethical standards of the institutional and/or national research committee and with the 1964 Helsinki declaration and its later amendments or comparable ethical standards. Ethical clearance was obtained from the University and informed consent was obtained from all individual subjects included in the study.

\section{Acknowledgements}

None

\section{Competing Interests Statement}

The authors declare that there are no competing or potential conflicts of interest.

\section{References}

American College of Sports Medicine. (2013). ACSM's guidelines for exercise testing and prescription (9th ed.). Baltimore: Lippincott Williams \& Wilkins.

Atlantis, E., \& Baker, M. (2008). Obesity effects on depression: systematic review of epidemiological studies. International Journal of Obesity, 32(6), 881-891. https://dx.doi:10.1038/ijo.2008.54

Barkin, S. L., Heerman, W. J., Warren, M. D., \& Rennhoff, C. (2010). Millennials and the world of work: the impact of obesity on health and productivity. Journal of Business and Psychology, 25(2), 239-245. https://dx.doi:10.1007/s10869.010.9166.5

Bodymedia. (2014). Bodymedia Fit Manual CORE Armband and Display. Retrieved from https://www.bodymedia.com/Support-Help/Bodymedia-Fit-CORE

Burkhauser, R. V., \& Cawley, J. (2008). Beyond BMI: the value of more accurate measures of fatness and obesity in social science research. Journal of Health Economics, 27(2), 519-529. https://dx.doi:10.1016/j.jhealeco.2007.05.005

Chan, C. B., Ryan, D. A., \& Tudor-Locke, C. (2004). Health benefits of a pedometer-based physical activity intervention in sedentary workers. Preventive Medicine, 39(6), 1215-1222. 
Cutler, D. M., Glaeser, E. L., \& Shapiro, J. M. (2003). Why have Americans become more obese? The Journal of Economic Perspectives, 17(3), 93-118.

De Cristofaro, P., Pietrobelli, A., Dragani, B., Malatesta, G., Arzeni, S., Luciani, M., \& Battistini, N. C. (2005). Total energy expenditure in morbidly obese subjects: a new device validation. Obesity Research, 13, A175.

De Zwaan, M., Petersen, I., Kaerber, M., Burgmer, R., Nolting, B., Legenbauer, T., \& Herpertz, S. (2009). Obesity and quality of life: a controlled study of normal-weight and obese individuals. Psychosomatics, 50(5), 474-482. https://dx.doi:10.1016/S0033-3182(09)70840.0

Dwyer, T., Hosmer, D., Hosmer, T., Venn, A. J., Blizzard, C. L., Granger, R. H., \& Dunstan, D. (2007). The inverse relationship between number of steps per day and obesity in a population-based sample-the AusDiab study. International Journal of Obesity, 31(5), 797-804.

Escoto, K. H., French, S. A., Harnack, L. J., Toomey, T. L., Hannan, P. J., \& Mitchell, N. R. (2010). Work hours, weight status, and weight-related behaviors: a study of metro transit workers. International Journal of Behavioral Nutrition and Physical Activity, 7(91), 1176-1186. https://dx.doi:10.1186/1479-5868-7-91

Fogelholm, M., Kronholm, E., Kukkonen-Harjula, K., Partonen, T., Partinen, M., \& Härmä, M. (2007). Sleep-related disturbances and physical inactivity are independently associated with obesity in adults. International Journal of Obesity, 31(11), 1713-1721.

Forhan, M. A., Law, M. C., Taylor, V. H., \& Vrkljan, B. H. (2012). Factors associated with the satisfaction of participation in daily activities for adults with class III obesity. Occupation, Participation and Health, 32(3), 70-78. https://dx.doi:10.3928/15394492-20111028-01

Gonnissen, H. K., Adam, T. C., Hursel, R., Rutters, F., Verhoef, S. P., \& Westerterp-Plantenga, M. S. (2013). Sleep duration, sleep quality and body weight: Parallel developments. Physiology \& Behavior, 121, 112-116. https://dx.doi:10.1016/j.physbeh.2013.04.007

Harper, A. (1998). Development of the World Health Organisation WHOQOL-BREF quality of life assessment. Psychological Medicine, 28(3), 551-558.

Hill, J. O., Peters, J. C., Catenacci, V. A., \& Wyatt, H. R. (2008). International strategies to address obesity. Obesity Reviews, 9(s1), 41-47. https://dx.doi:10.1111/j.1467-789X.2007.00437.x

James, W. P. (2005). Obesity. The Lancet, 366, 1197-1209.

Johnstone, A. M., Murison, S. D., Duncan, J. S., Rance, K. A., \& Speakman, J. R. (2005). Factors influencing variation in basal metabolic rate include fat-free mass, fat mass, age, and circulating thyroxine but not sex, circulating leptin, or triiodothyronine. The American Journal of Clinical Nutrition, 82(5), 941-948.

Kessler, R. C., Barber, C., Beck, A., Berglund, P., Cleary, P. D., McKenas, D., \& Wang, P. (2003). The world health organization health and work performance questionnaire (HPQ). Journal of Occupational and Environmental Medicine, 45(2), 156-174.

Leibel, R. L., Rosenbaum, M., \& Hirsch, J. (1995). Changes in energy expenditure resulting from altered body weight. New England Journal of Medicine, 332(10), 621-628.

Li, J., O'Connor, L. E., Zhou, J., \& Campbell, W. W. (2014). Exercise patterns, ingestive behaviors, and energy balance. Physiology \& Behavior, 134, 70-75. https://dx.doi:10.1016/j.physbeh.2014.04.023

MacArdle, W. D., Katch, F. I., \& Katch, V. L. (2010). Exercise physiology: Nutrition, energy, and human performance (7th ed.). Philadelphia: Wolters Kluwer-Lippincott Williams \& Wilkins Health.

Micklesfield, L. K., Lambert, E. V., Hume, D. J., Chantler, S., Pienaar, P. R., Dickie, K., ... Goedecke, J. H. (2013). Socio-cultural, environmental and behavioural determinants of obesity in black South African women. Cardiovascular Journal of Africa, 24(9-12), 369-75. https://dx.doi:10.5830/CVJA-2013-069

Miranda, H., Gore, R. J., Boyer, J., Nobrega, S., \& Punnett, L. (2015). Health behaviors and overweight in nursing home employees: contribution of workplace stressors and implications for worksite health promotion. The Scientific World Journal, 2015, 1-10. https://dx.doi:10.1155/2015/915359

Nishitani, N., Sakakibara, H., \& Akiyama, I. (2012). Characteristics of short sleeping time and eating behaviors related to obesity. Obesity Research \& Clinical Practice, 6(2), e103-e109. https://dx.doi:10.1016/j.orcp.2011.06.002

Peer, N., Steyn, K., Lombard, C., Lambert, E. V., Vythilingum, B., \& Levitt, N. S. (2012). Rising diabetes prevalence among urban-dwelling black South Africans. PloS One, 7(9), e43336. 
https://dx.doi:10.1371/journal.pone.0043336

Quist, H. G., Christensen, U., Christensen, K. B., Aust, B., Borg, V., \& Bjorner, J. B. (2013). Psychosocial work environment factors and weight change: a prospective study among Danish health care workers. BMC Public Health, 13(1), 1-8. https://dx.doi:10.1186/1471-2458-13-43

Robertson, R. J. (2004). Evaluation of the Sense Wear Pro Armband to assess energy expenditure during exercise. Medicine and Science in Sports and Exercise, 36, 56-61.

Sartorius, B., Veerman, L. J., Manyema, M., Chola, L., \& Hofman, K. (2015). Determinants of obesity and associated population attributability, South Africa: Empirical evidence from a national panel survey, 2008-2012. PloS One, 10(6), e0130218. https://dx.doi:10.1371/journal.pone.0130218

Skevington, S. M., Lotfy, M., \& O'Connell, K. A. (2004). The World Health Organization's WHOQOL-BREF quality of life assessment: psychometric properties and results of the international field trial. A report from the WHOQOL group. Quality of Life Research, 13(2), 299-310.

Solovieva, S., Virtanen, M., \& Viikari-Juntura, E. (2013). Review. Scandinavian Journal of Work \& Environmental Health, 39(3), 241-258. https://dx.doi:10.5271/sjweh.3364

Taylor, V. H., Forhan, M., Vigod, S. N., McIntyre, R. S. \& Morrison, K. M. (2013). The impact of obesity on quality of life. Best Practice \& Research Clinical Endocrinology \& Metabolism, 27(2), 139-146. https://dx.doi:10.1016/j.beem.2013.04.004

Tibazarwa, K., Ntyintyane, L., Sliwa, K., Gerntholtz, T., Carrington, M., Wilkinson, D... Stewart, S. (2009). A time bomb of cardiovascular risk factors in South Africa: results from the Heart of Soweto Study "Heart Awareness Days". International Journal of Cardiology, 132(2), 233-239. https://dx.doi:10.1016/j.ijcard.2007.11.067

Van Zyl, S., Van der Merwe, L. J., Walsh, C. M., Groenewald, A. J., \& Van Rooyen, F. C. (2012). Risk-factor profiles for chronic diseases of lifestyle and metabolic syndrome in an urban and rural setting in South Africa. African Journal of Primary Health Care \& Family Medicine, 4(1), 1-10. https://dx.doi:10.4102/phcfm.v4i1.346

World Health Organization. (2014). World Health Statistics 2008. Retrieved from https://www.who.int/gho/publications/world_health_statistics/EN_WHS08_Full.pdf

World Health Organization. (2015a). Obesity and Overweight Fact Sheet. Retrieved from https://www.who.int/mediacentre/factsheets/fs311/en/p1-5.

World Health Organization. (2015b). Obesity: preventing and managing the global epidemic. Retrieved from https://www.who.int/nutrition/publications/obesity/WHO_TRS_894/en/

\section{Copyrights}

Copyright for this article is retained by the author(s), with first publication rights granted to the journal.

This is an open-access article distributed under the terms and conditions of the Creative Commons Attribution license (http://creativecommons.org/licenses/by/4.0/). 